\title{
Designing Localized Teaching Aids for Sustainable Use through Human-Centered Design in Rural Vietnam
}

\author{
Youngchan Jeong and Namjun Kang
}

\begin{abstract}
The goal of this study was to provide sustainable science teaching aids to a primary school in the rural area of Vietnam. To solve a sustainability issue, field research, an ideation workshop, and prototyping workshops were conducted, following the HCD Toolkit designed by IDEO. A co-creation workshop was also conducted to modify the final product with teachers of the school. Finally, six kinds of science teaching aids were applied at the primary school. The result, although it has some limitations, showed that HCD is an effective way to design a localized science teaching aids for long-term use.
\end{abstract}

Index Terms-Educational development, educational cooperation, science teaching aid, primary education.

\section{INTRODUCTION}

"How can we make more sustainable educational support in a short-term volunteer program in a developing country?" This study was motivated by this rough question.

After spreading the concepts, such as global citizenship, altruism, and multiculturalism, many students joined the international volunteer program of the universities or the youth organizations. Many volunteer programs have educational parts to do some activities with local students. Certainly, there are benefits to the volunteer program [1], [2]. However, many negative influences were also observed [3], [4]. The primary cause of the negative impact is the lack of consideration of a sustainability, local contexts, local cultures and after effects to the local society.

Especially in short-term volunteer programs, the lack of these considerations is a serious issue. Volunteers who want to perform work solely based on their own opinions could neglect locals' desires [3]. As a result of this, the volunteers' endeavors can easily fade after a while. This is because the products and programs that they deliver without considering the locals' desires, contexts and cultures could be the ill-fitting clothes to the host community. For this reason, the products would become gradually useless and be eventually sold or abandoned.

The goal of this study is to examine the HCD process as an effective way to make a sustainable product that supports the problems of the host community in a short-term volunteer project.

We focused on primary education. First, primary education is one of the most important issues in a developing country, and it has been declared so by Millenium

Manuscript received July 15, 2016; revised January 22, 2017.

Youngchan Jeong is with the Seoul National University, South Korea (e-mail: ycmailcase@gmail.com).

Namjun Kang is with the Department of Communication, Seoul National University, South Korea (e-mail: njkang@snu.ac).
Development Goals of UN and also included in Sustainable Development Goals of UN. The second reason is that the effect of volunteerism could remain longer in an education field than physical works, such as construction, installation, and material supply.

In this study, the HCD Toolkit [5] was employed to make more sustainable outcomes in short-term volunteer assignments in the developing country. The HCD Toolkit has been specially adapted for organizations working with developing countries [5]. The kit emphasizes three concepts in order to design proper and successful solutions. These include desirability, feasibility, and viability. These three concepts can be replaced with the following questions: "What do people desire?"; "What is technically and organizationally feasible?"; and "What can be financially viable?" [5]. Researchers designed the solution in order to answer these questions.

This research is part of the volunteer program of Seoul National University (SNU) and Korea Hydro and Nuclear Power Co., LTD (KHNP). The volunteer team consisted of twenty undergraduate students, twelve employees of KHNP, five administrative staffs of SNU, two experts of water purification, and one expert of HCD and research. Also, the team cooperated with a Korean organization in Vietnam to translate languages and manage the logistics.

This research was carried out in Phuoc An 3 primary school in Binh Dinh province, Vietnam. The target area of this study is the rural region of Quy Nhon city, which is in central Vietnam. We worked with the ministry of foreign affairs of the Binh Dinh province government that has an authority to manage volunteer works by foreigners in this region. The officers of this organization reported to our team about several public schools that already requested support. After visiting these schools, we compared and analyzed the reported problems. Considering the manpower and skills of the research team, we chose one school to work with. Because of the institutional sameness of Vietnam, this school was considered to be in the standard public educational condition.

In this study, the field research, including the observation and interview, was carried out in the rural region of Vietnam. After analyzing and understanding the results of the research, a co-creation workshop was carried out in Vietnam to make a final product with the teacher who will use the teaching aids. Through this process, we designed and supplied sustainable teaching aids to the primary school in the rural area of Vietnam.

\section{GOAL}


Main goal of this study is examining HCD toolkit as an effective way to design localized teaching aids in short-term volunteer program. To do this, we did a field study in Vietnam region and answering the questions:

1) In teaching and learning situations, what are the defective points of the primary school in Phuoc An 3 Elementary?

The first goal of this research is finding out specific problems of education in a Phuoc An 3 primary school. Primary schools in rural areas like this school have many issues such as a lack of educational materials, playgrounds, and teachers. This school already requested educational support from our team. To design a solution, first, we must know about the problem and the possible causes of this complication.

2) How can we design and implement adaptable solutions to support these issues? - The second goal is to make adaptable solutions solve these obstacles. The meaning of "adaptable" consists of three concepts: desirability, viability, and feasibility, which are borrowed from the HCD Toolkit. We examined this toolkit to create a more sustainable solution.

\section{METHOD}

In this study, researchers set design steps following the HCD Toolkit developed by the IDEO company [5]. Referencing the three stages of the toolkit, we conducted the field research, ideation process, and delivery rule. The entire process of this study is shown here. (See Fig. 1).

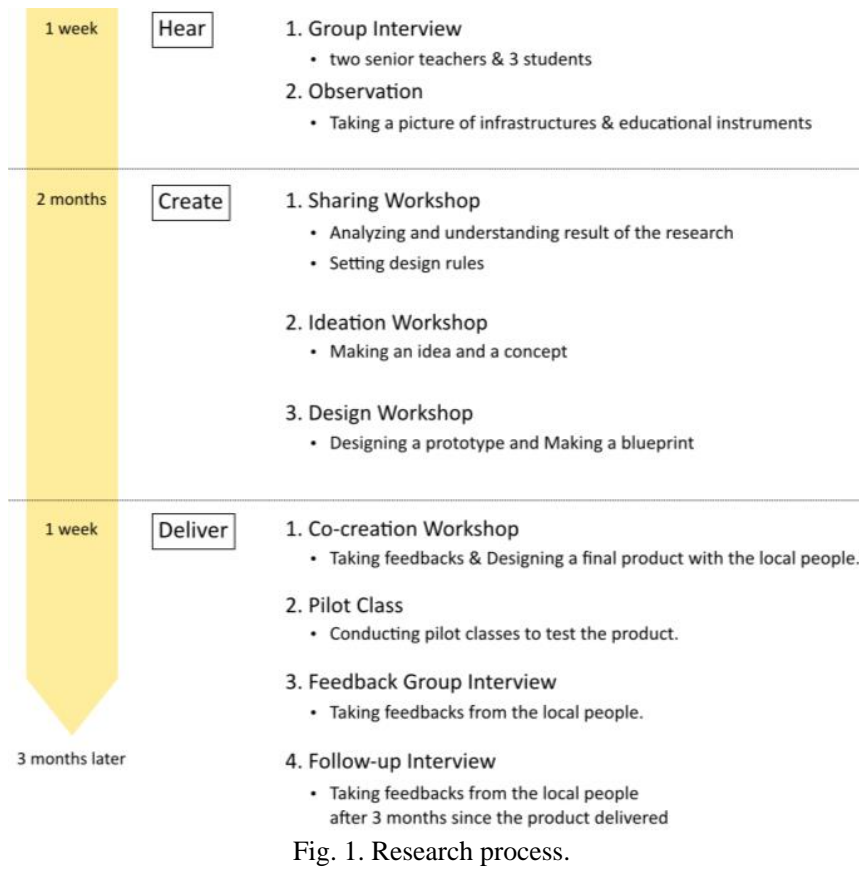

\section{A. Hear}

In the first visitation, several pieces of information about the school infrastructure were collected. As described above, using this information, the researchers chose one school to work with. After the first visitation, field research was conducted to learn the details of the education circumstances and to find out problems in the teaching and learning situation.

\section{1) Interview with teachers}

Two senior teachers were interviewed face-to-face in a group for approximately $1 \mathrm{~h} 30 \mathrm{~m}$. We conducted a semi-structured interview. The conversation in the interview was translated by a Vietnamese expert who majored in the Korean language. Teachers were different in terms of gender, age, and the subject they teach. The male teacher was 54 years old and was a general teacher who teaches all subjects except special subjects like English, music, fine arts, and physical education. The other was a 43-year-old English teacher. Both of them were born and raised in Phuoc An 3.

The interview was focused on the system and policy of the school, the teaching and learning methods, and the issues that they suffered from. The questions for the teachers were related to: Administrative logistics, Teaching and learning circumstances in the regular class and after-school classes, Defective points of the class or the school, Overall income and outcome of households in this area, The policy of the educational authorities, Infrastructures and materials in this school

\section{2) Interview with students}

Three students were interviewed face-to-face in a semi-structured group form. They were interviewed for approximately $1 \mathrm{~h} 30 \mathrm{~m}$. The conversation was translated by a Vietnamese that specialized in the Korean language. Students were different in gender and grade. One student was female and in the 5 th grade. Another student was male and in the 4th grade. The other student was female and in the 3 rd grade. The questions for the teachers were related to: Favorite subject and reason, Difficult subject and reason, The way and time required to commute to school, The reason they study, How they study for the examination, Defective points of the class How they play with friends

\section{3) Observation}

In addition to the interview, researchers captured images of several scenes of the school in order to learn about the school's infrastructure and materials. Researchers took pictures and short video clips of classrooms, offices, a library, stairs, course books, a computer lab, and a toilet.

\section{B. Create}

After we complete the "Hear" phase, we carried out eight workshops in two months in order to understand data, define our design opportunity, make a design concept, and design prototypes for the issue to solve.

Following the HCD Toolkit, this study conducted a sharing workshop to review the result of each research process. After sharing the data, researchers identified the patterns of the data. We used an affinity diagram method to find out the common things in a data set.

Depending on these understandings, we defined our design opportunity for each issue. In this phase, several design ideas and regulations were discussed. Following these regulations, we conducted an ideation workshop to share ideas and to make a design concept. In this workshop, researchers were distributed in three groups and suggested their teaching aid.

After creating the concept, we had a design workshop four times to develop the idea and to design prototypes. In this 
process, each design team showcased its prototype and gave feedback to another team. According to the feedback, each team elaborated on its idea and prototype iteratively.

Also, we recorded these presentations and made several documents of idea and prototypes in the Vietnamese language. We sent these papers and videos to the Phuoc An 3 school to receive comments from the locals. Finally, in this creation phase, we made a blueprint and a manual of each teaching aid. We did not make a complete product while we planned the co-creation workshop in order to make the teaching aids with the teachers of the school.

\section{Deliver}

Following the second research question, we set several rules and steps to make the teaching aid more viable and feasible. In the first phase of the implementation process, we conducted a co-creation workshop to capture the teachers' opinions and to check the adaptability of the teaching aids. In this workshop, we brought manuals and samples of the teaching aids. After introducing these materials, researchers and the teachers made these teaching aids together and discussed the points at which they could be improved. Reflecting the result of the co-creation workshop, researchers made the modified version of the teaching aids.

After the modifying process, pilot classes were conducted to test these teaching aids. We set six kinds of pilot classes to test each teaching aid. In this pilot class, the teachers used the teaching aid, while researchers only observed the usage behavior and responses of the students. In order to avoid the intervention effect, only one or two researchers attended each pilot class.

Finally, two kinds of the feedback process were conducted to get feedback. The first step is a group interview. Eight teachers, an assistant principal, and the principal were interviewed in an open-ended form for approximately $1 \mathrm{~h}$ $30 \mathrm{~m}$. The main questions in this interview included the following: Is it difficult to use this teaching aid?, What is the wrong point of each teaching aid?, Can you make and use this teaching aid alone?, Will you use this teaching aid in the long term?

Also, to learn the viability and feasibility of the teaching aid, we checked the usage status of the aids three months after. A Korean organization in Vietnam, which cooperated with this study, met teachers and asked about teaching aid usage.

\section{RESULT}

\section{A. Hear}

The researchers reviewed and discussed all the results of the field research in the sharing workshop. The interview demonstrated several important facts and issues of the Phuoc An 3 primary school.

\section{1) Basic information}

First, we gathered information on infrastructure and administrative logistics. Three hundred thirteen students were in this school and distributed in 13 classes. Ten classes were operated in the main school, while three classes were operated in the sub-school because of the commute distance issue. Twenty-six teachers worked in this school, and the government certified all of them. One computer lab that equipped eight Windows XP PCs and one library were operated. About three to five percent of the students were flunked per a year.

\section{2) Lack of educational instrument in the school}

The main problem of this school was the shortage of teaching materials. There was no science lab. Also, only one beam projector was attached to one classroom. Moreover, there was no printer capable of printing large images. Students used the textbooks only in their study because there were no reference books.

For these reasons, the subjects of science and geography were difficult to teach and understand. In the interview, the male teacher said, "Many things need visual references to explain. For example, suppose I explain about the solar system or the Earth. However, teachers did not have visual references, so students cannot fully understand these concepts." Students also commented on the lack of references: "The teacher showed us a big map in geography class. However, we cannot see because the map is the only one. To see the map, we had to go in front of the blackboard one by one. It is awkward."

\section{3) Design limitations}

According to the results of the interview and observation, in Vietnam, several limitations were set to foreign activities in the area of education. The interviewees gave negative responses to the making of a new curriculum or new subject, and there was a practical reason for this reply. They commented that even if a new curriculum was created, there are not sufficient teachers to maintain the classes in the long term. All the teachers already have a fixed role.

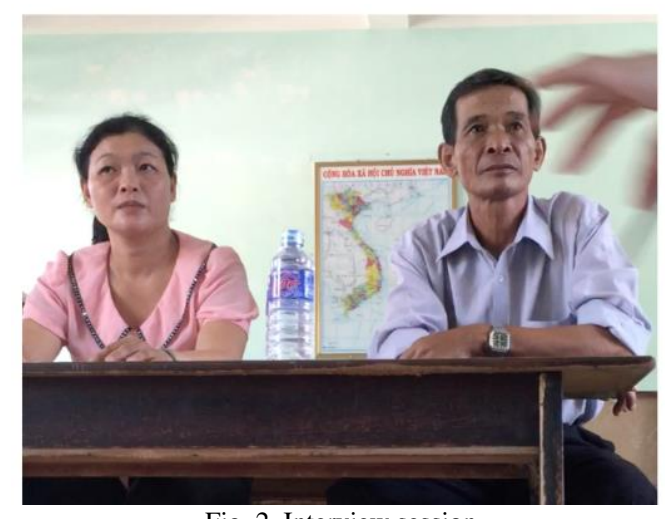

Fig. 2. Interview session.

\section{B. Create}

\section{1) Rules and goals of the design process}

According to the results of the hearing phase, we defined design rules and objectives in the final step of the sharing workshop.

Firstly, we cannot make a special class or a new curriculum because there were limitations to design. Also, following the HCD Toolkit, we had to consider viability and feasibility in our product design. Therefore, we decided to make visual teaching aids. With the lack of educational materials, students could not fully understand the concepts that cannot be observed with their own eyes. For example, by analyzing the textbooks in the sharing workshop, we found 
terms like human organs, a polar bear, evaporation, and germs, all of which cannot be fully understood without visible examples.

Second, we focused on the textbook (see Fig. 3). Following the textbook, we thought we would be able to achieve high acceptability because teachers in this school already taught the themes and concepts of the teaching aids. Also, this was not a new curriculum or special class that the school did not want to accept.
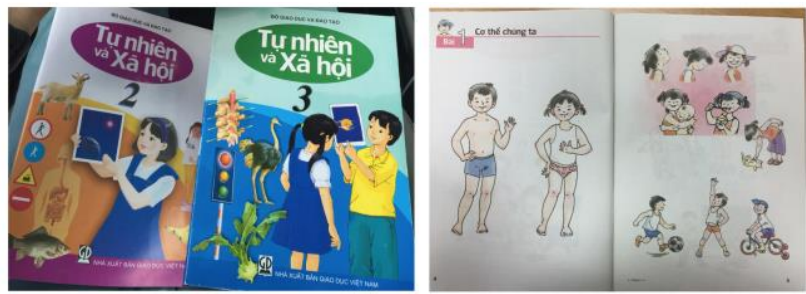

Fig. 3. Textbooks of the Phuoc An 3 primary school.

Third, we selected a science subject. In the hearing phase, teachers and students need a lot of scientific materials. Although the school had some educational instruments, these things were difficult to use and understand. Another reason for this selection is to avoid miseducation. The school taught nine subjects. In these subjects, science had the most common themes as compared to that of Korea. To avoid conveying improper knowledge to students, we did not select the subject, such as history or language, which the researchers did not learn.

Fourth, the aids could be easy to make. Basically, these aids were additional work for the teachers. If they are difficult to make and use, then they will not use them at all. Also, the aid can be made by local resources. If we bring materials that can only be bought in Korea, they cannot fix or customize their teaching aids. It might harm the viability and feasibility. Finally, the resources must be cheap. The teaching aids will be difficult to maintain if the materials are expensive.

\section{2) Ideation workshop}

After the sharing workshop, researchers were distributed into three teams that were named Two, Three, and Four, and they each took charge of the three grades. We focused on grades two, three, and four because the school had changed semesters, so there were no freshmen (grade one), graduate students (grade five). Following this circumstance, each team was tasked to make a teaching aid for its focused grade.

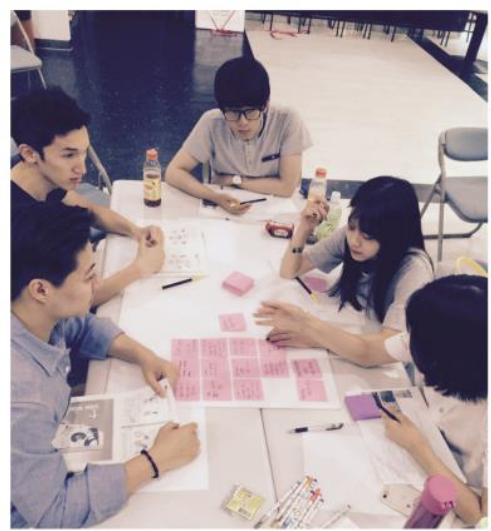

Fig. 4. Workshops in the creating process.
At first, each team had more than ten ideas from the textbook. For this, the teams translated the textbook contents of each grade to the Korean language. Also, they completed secondary research using the Internet.

In the workshop, the teams had a presentation about the idea and the result of the desk research. Ideas contained a rough version of the making manual of the aid. After the presentation, we discussed each idea, following the criteria such as desirability, viability, and feasibility. Then we voted and picked two ideas for each grade (see Table I.)

TABLE I: THEMES OF TEACHING AIDS FOR EACH GRADE

\begin{tabular}{lll}
\hline \hline & Teaching aid1 & Teaching Aid 2 \\
\hline Grade 2 & $\begin{array}{l}\text { How do the bones and the } \\
\text { muscles inside the human } \\
\text { hand work? }\end{array}$ & $\begin{array}{l}\text { How to fold and unfold } \\
\text { arms? }\end{array}$ \\
Grade 3 & $\begin{array}{l}\text { How do the planets of the } \\
\text { solar system revolve? }\end{array}$ & How do humans breathe? \\
Grade 4 & $\begin{array}{l}\text { Experience the cohesive } \\
\text { force of water. }\end{array}$ & $\begin{array}{l}\text { Animals live on another side } \\
\text { of the planet. }\end{array}$ \\
\hline \hline
\end{tabular}

Also, we recorded these presentations and sent them to the Phuoc An 3 school in order to get feedback from local people.

\section{3) Design workshop}

Following the rules set by the sharing workshop and the themes made by the ideation workshop, we designed prototypes of the teaching aids. In the first design workshop, the entire team completed a secondary research about its theme and existing teaching aids. Also, the teams made a rough paper prototype for each theme. Then, we selected, combined, and converted the idea according to the rules. Furthermore, we changed the materials of the product to those that can be bought in Vietnam as much as possible.

For example, Team 3 suggested three kinds of ideas for the theme "How do the planets of the solar system revolve?" The first idea was to design Dymaxion maps to visualize the spherical shape of the globe. A Dymaxion map is a sort of origami method of making a sphere using paper. (See Fig. 5.)
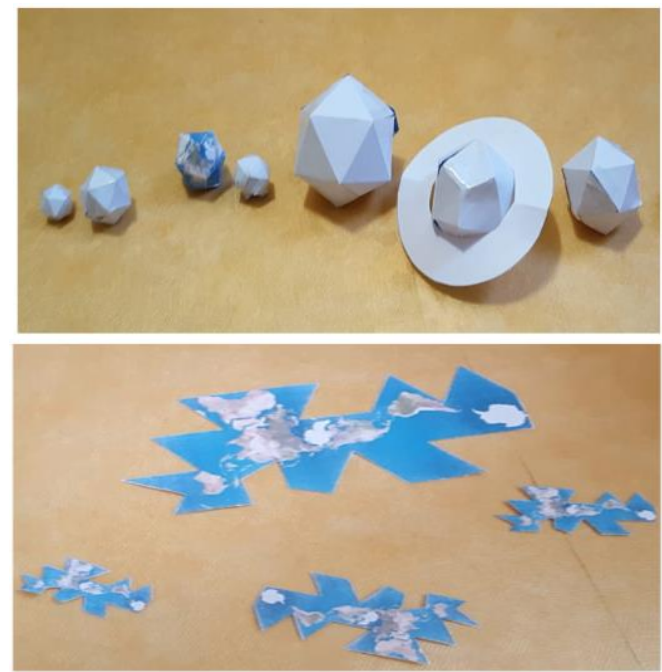

Fig. 5. Dymaxion maps for grade 3.

The second idea was making a movable mobile by using thread, wire, and acrylic panels. It can show the mobility of the rotation of the planet. The third idea was making several concentric circles using paper to demonstrate the track of the 
planet. We selected the first idea because that prototype made it easy to show the shapes. Also, we combined the second idea, which can demonstrate mobility. As such, Team 3 made a movable Dymaxion map in the prototype session.

After the first design workshop, we sent an email to the Phuoc An 3 school to get approval for each prototype. In the second workshop, each team made the prototype (Fig. 6) and recorded a demo video to explain the process of making it in the third workshop.

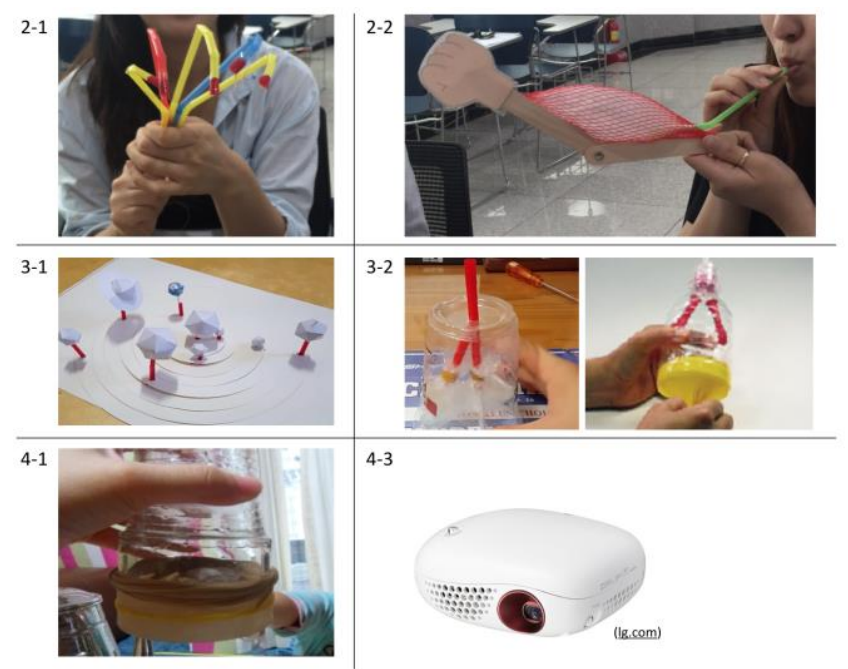

Fig. 6. Prototypes of aids for each grade.

Details of each aid:

2-1: How do the bones and muscles in the human hand work? - Using straws and strings, we make a movable prototype of a human hand. This model can easily show functions of the muscle to move hand bones.

2-2: How do arms fold and unfold? - Find out through a ready-made toolkit that can be assembled easily. This toolkit shows the muscle movement in the human arm. Also, each element in this toolkit can be replaced by local materials.

3-1: How do the planets of the solar system rotate and revolve? - Make a movable Dymaxion map to show the shape of the globe. Also, it can display the rotational movement of the planets.

3-2: How do humans breathe? - Using a plastic cup, straws, and small balloon, this team made a miniature version of the human lung. It shows the inhalation and exhalation process by expanding and contracting the balloon.

4-1: Experience cohesive force of water - Using a stocking and a plastic cup, it can display how all the water in the cup cannot pass the stocking simultaneously because of the cohesive feature.

4-2: Animals live on another side of the planet - A battery embedded in a small beam projector thereby collects and organizes the image and video resources of various animals; this team made a source book for the textbook. The sources are free to share and are stored in a beam projector. This projector can be used anytime and anywhere because of the battery feature.

Finally, the team had a rehearsal to demonstrate a prototype and explain features to the expert. In this final session, several experts and all the team members attended and provided comments for each prototype. Also, we made an instruction document of each prototype in the Vietnam language to send to the Phuoc An 3 school.

\section{Deliver}

Before delivering, we made a material list of each aid. We sent this list to a local agency to buy the materials in the Vietnam market. We did not bring the complete product but planned to assemble the teaching aid with the teachers in Vietnam.

\section{1) Co-creation workshop}

Visiting the Phuoc An 3 school in Vietnam, we had a workshop to introduce the features of the teaching aid and to develop the final product together (Fig. 7).

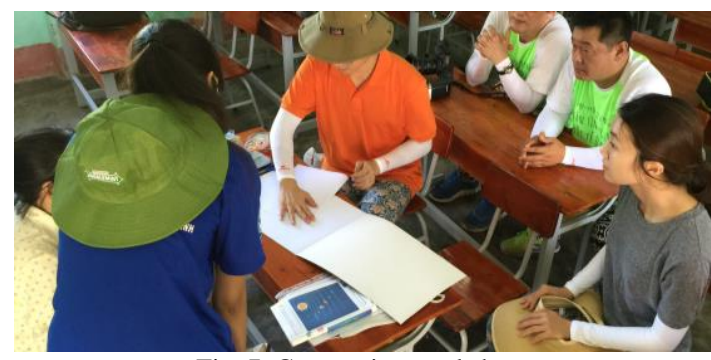

Fig. 7. Co-creation workshop

Each team worked with the teachers who were in charge of each grade. The teachers learned the method of making the aid and provided comments about the aid. Almost every feature that the researchers had designed was easily understood because the themes were selected from the textbook that they used. However, some features had to be modified.

For example, for the human hand theme, the teacher suggested that the string may be vulnerable to long-term use. Also, for the planet theme, the teacher said, "I can understand the making method of Dymaxion map, but the students would not be able to make this." Moreover, for the beam projector theme, the teachers took a long time to understand the file architecture.

Following the results of the co-creation workshop, the researchers modified some of the teaching aids. We searched for and purchased more durable strings for the human hand aid, and we replaced the concentric circle of the Dymaxion map with a flat-shaped planet miniature to make the model easier (Fig. 8) Also, we re-designed the file architecture and quantity based on the teachers' needs.

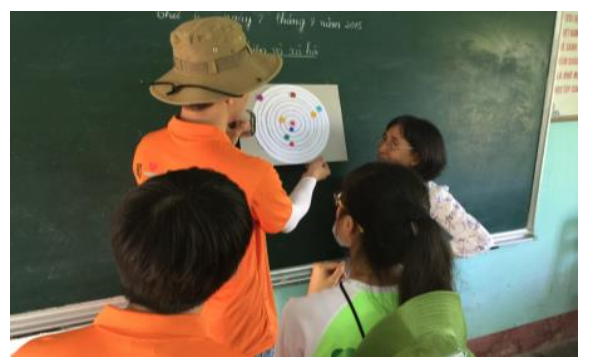

Fig. 8. Modified version for dymaxion map following teachers' opinion.

\section{2) Pilot class}

After co-creation and modifications, we set six pilot classes to test the aids in the real context (Fig. 9).

All the students in grades 2, 3, and 4 were invited to participate in these classes. To test the aids in a real classroom situation, we limited our role. In the class, the 
teacher taught the theme using the aids, and researchers stood in the back of the classroom or even outside of the classroom. Each pilot class proceeded in an hour following the general condition.

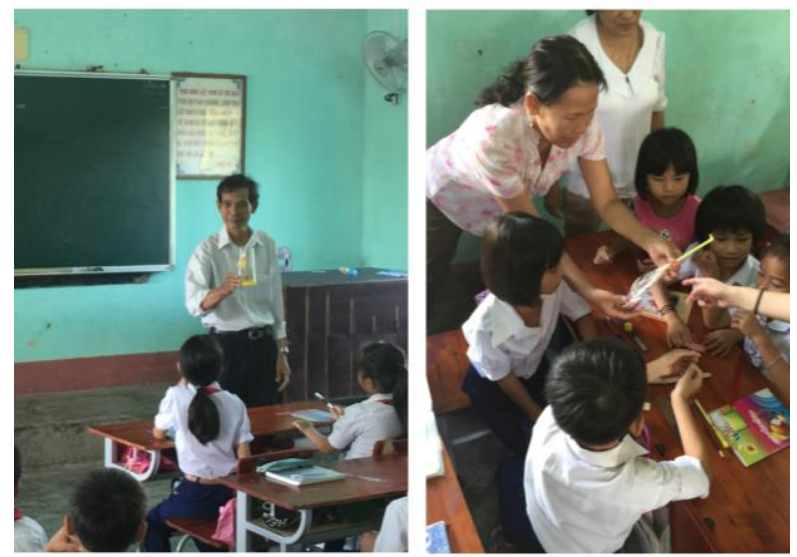

Fig. 9. Pilot classes.

\section{3) Feedback interview}

After the pilot class, we set a feedback interview to gather the feedback and responses. Almost every teacher showed positive reactions, but there was still feedback to consider.

The teachers commented: "Before theses aids, I typically drew to teach these themes, but it was difficult. By using these aids, I can teach more easily than drawing"; "It is good to localize fully in the material, so I can get the materials easily in the nearby market"; "The good point of this aid is modifiability. I can modify the teaching aid myself because it dealt with the concepts of the textbook"; and, "Students were more active than formal classes."

However, they also said, "I was not good at using this beam projector this time, but I can be proficient with practice"; "I think there are difficult things to make"; and, "Because here is a lack of stuff to play, so the students want to bring these teaching aids home. It can be a problem."

Finally, reflecting on the final result, we bought and stored plenty of materials to use these aids for at least seven years in the school.

\section{4) Follow-up interview}

Three months since the aids were delivered, we set a follow-up interview. The local organizer who worked with us on the previous steps of this research met the president of the school to ask about the aid usage.

The aids were properly used in the class after they were supplied. Also, the sub-school they ran in the distant rural area used the aids. This result was not intended, but the teachers thought the aids were effective, so they adapted their use to another school.

\section{DISCUSSION}

From the results provided, it is clear that we found the main problem of the Phuoc An 3 primary school. Almost all students learned from textbooks only. Moreover, teachers experienced difficulty in teaching because of this issue. This study designed the teaching aids depending on the field research and HCD rules. During the study, the following issues were found.

\section{A. Acceptability and customization}

Acceptability is the most important issue that must be achieved in this study. Without acceptability, the value of the short-term volunteer program would depreciate. Simply, the products or services that the volunteers brought could be forgotten without sustainability. Moreover, it could have adverse effects on the host community.

HCD research was valid to promoting the acceptability of the design product. In this study, several interviews were conducted to gather the desires and opinions of the local people. In addition to this local-based approach, the designs were based on the textbook that they used. In doing so, the teachers were easily encouraged to participate in the design process.

Moreover, we built almost every idea in the process of checking and approving. Also, we provided the co-creation session so that the teachers could make their own products by hand. By doing so, their attitudes to the product became positive. These are the steps that promote acceptance. Without them, we would have designed products that were unfit for the local people.

\section{B. Localization}

Localization is one of the essential elements of sustainability. If the teachers cannot make or fix the product using local materials, then the product cannot be used for a long time, even if the product seems good during its first use. We designed four teaching aids that can be made from local materials. One material can be replaced by a local product; however, the beam projector cannot be repaired in this region. Also, we supply additional materials that can cover seven years' usage.

In doing so, the teachers can easily buy the materials in the nearby market. Therefore, the sustainability of the product will improve. For the last one, we discussed an alternative method, such as with the use of a micro storage card of the projector in their PC lab.

\section{Expandability}

Because of the limitations on time and budget, the short-term volunteer project can work with just one organization at a time. However, if the products that the team delivers can be used in another place, the effect of the activity will be multiplied.

In this study, the textbooks that the school already used were employed as an essential reference. We focused on the contents of the textbook only and did not add other information. In doing so, the teachers used the teaching aids in another school: their sub-school. The textbook was the same, so they just used the aids without modifying or customizing them.

\section{Effectiveness}

The design process and its result can effectively support education. Before the teaching aids were supplied, the students only learned concepts such as the earth or muscles through print-outs on textbooks. The students should imagine that to understand. However, after the teaching aids were supplied, this visibly designed instrument showed the 
concepts in an easier to understand way

\section{CONCLUSION}

The goal of this study was applying HCD to provide adaptable and sustainable science teaching aids to a primary school in a rural area in Vietnam. In the first phase, we conducted field research to find out the problems in the Phuoc An 3 primary school, which was that almost every student learned from a textbook only.

We could have just brought the science aid box or the conventional products, but we did not because the aids designed for science education in developing countries are relatively expensive and inadaptable to the rural area of Vietnam.

Therefore, we designed six kinds of science teaching aids that reflect the voices of the field. Also, we checked the usability in a perspective of feasibility and viability. These teaching aids dealt with their existing curriculum and textbook, so they gained high acceptability.

However, this study targeted just one rural primary school in Vietnam. Also, only six teaching aids of several themes in the science textbooks were designed. So, in the future study, we will test this process in another region, and we will design more teaching aids that can cover more subjects in primary education.

Although these limitations exist, this study found out the positive role of HCD in the short-term volunteer projects. Using HCD, the sustainability of the volunteer project would be promoted more.

\section{ACKNOWLEDGMENT}

This research was performed by support from the Institute for Global Social Responsibility of Seoul National University and Korea Hydro and Nuclear Power Co., LTD.

\section{REFERENCES}

[1] N. G. McGehee and K. Andereck, "Volunteer tourism and the "voluntoured": the case of Tijuana, Mexico," Journal of Sustainable Tourism, vol. 17, no. 1, pp. 39-51, Jan. 2009

[2] A. J. McIntosh and A. Zahra, "A cultural encounter through volunteer tourism: Towards the ideals of sustainable tourism?" Journal of Sustainable Tourism, vol. 15, no. 5, pp. 541-556, Sep. 2007.

[3] D. A. Guttentag, "The possible negative impacts of volunteer tourism," International Journal of Tourism Research, vol. 11, no. 6, pp. 537-551, Nov. 2009.

[4] K. Lyons, J. Hanley, S. Wearing, and J. Neil, Annals of Tourism Research, vol. 39, no. 1, pp. 361-378, Jan. 2012.

[5] IDEO. HCD Toolkit. (2015). [Online]. Available: http://www.ideo.com/work/human-centered-design-toolkit/

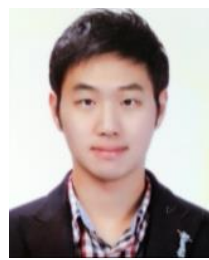

Youngchan Jeong is a Ph.D. student of Graduation School of Convergence Science and Technology, Seoul National University.

He majored in digital information convergence. His research interests include information and communication technology for development (ICT4D).

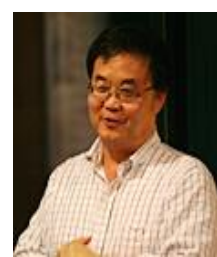

Namjun Kang is a professor of the Department of Communication, Seoul National University. 